\title{
A theoretical study of the reactions of carbonyl oxide with water in atmosphere: the role of water dimer
}

\author{
Andrew B. Ryzhkov, Parisa A. Ariya
}

\begin{abstract}
Carbonyl oxide is a well-known intermediate formed in gas-phase reactions of ozone with alkenes. Secondary reactions of carbonyl oxide are suggested to lead to the formation of HO, $\mathrm{H}_{2} \mathrm{O}_{2}$ and organic peroxides in the atmosphere. We performed a theoretical study of reactions of carbonyl oxide with water and a water dimer. Using CCSD(T)/6-311+G(2d,2p)//B3LYP/6$311+\mathrm{G}(2 \mathrm{~d}, 2 \mathrm{p})$ calculations we found that the most energetically favourable channel is the formation of hydroxymethyl hydroperoxide (HMHP) as the result of reactions of carbonyl oxide with the water dimer. The potential importance of water dimer reactions in the chemistry of the troposphere is discussed herein.
\end{abstract}

\section{Introduction}

Numerous volatile pollutants are contained within Earth's atmosphere. Nonmethane hydro-carbons constitute an important group of these volatile compounds and include unsaturated chemicals with both natural and anthropogenic origins [1]. Reactions of ozone with unsaturated compounds such as alkenes provide a significant pathway for atmospheric degradation, in addition to subsequent reactions with $\mathrm{HO}, \mathrm{NO}_{3}$ or $\mathrm{Cl}$ radicals [2]. Ozonolysis is one of the few reactions, which leads to the production of free radicals such as $\mathrm{HO}, \mathrm{HO}_{2} ; \mathrm{RO}_{2}$, and also organic peroxides from non-radical substances. It can also play a major role in the oxidative potential of the atmosphere [3-5].

It is widely accepted that ozonolysis of alkenes proceeds via carbonyl oxide (Criegee intermediate) that has first been suggested in the liquid phase [6], and has later been shown to be also applicable to the gas phase $[7,8]$.

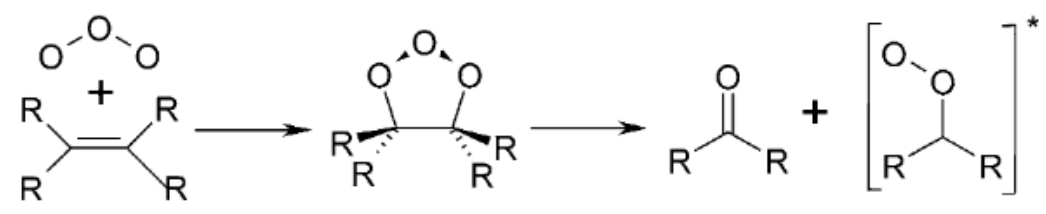

The primary stage of reaction (1) is the cyclo-addition of ozone to the double bond of an unsaturated compound, resulting in the formation of a primary ozonide. Subsequently, the ozonide undergoes cleavage, leading to the formation of a carbonyl compound and carbonyl oxide, having excess energy due to the high exothermicity of the reaction (e.g., 49. $2 \mathrm{kcal} / \mathrm{mol}$ for ethene $+\mathrm{O}_{3}[9]$ ). The excited carbonyl oxide can either unimoleculary decompose to yield species such as $\mathrm{CO}, \mathrm{CO}_{2} ; \mathrm{H}_{2}, \mathrm{H}$, and $\mathrm{H}_{2} \mathrm{O}$, or be collisionally stabilised. Under atmospheric conditions, the stabilization pathway for carbonyl oxide is assumed to account for $40 \%$ for ethene and varies from 3 to $40 \%$ for larger alkenes [8,10-13]. Stabilised Criege - intermediates can react with various atmospheric compounds, namely formaldehyde, acetaldehyde, $\mathrm{CO}, \mathrm{NO}_{\mathrm{x}}$ 
$\left(\mathrm{NO}_{\mathrm{x}}=\mathrm{NO}+\mathrm{NO}_{2}\right) ; \mathrm{SO}_{2}$ and $\mathrm{H}_{2} \mathrm{O}$ [7] and references therein. One of the most important reactions is considered to be the reaction with water [14].

It has been experimentally observed that the products of the ozonolysis reaction of alkenes in the presence of water are hydroxyl methyl hydro-peroxide (HMHP), formic acid, ketones and $\mathrm{H}_{2} \mathrm{O}_{2}$ [10,13,15-17]. Hatakeyama et al. [18] and Gaebet al. [19] proposed that $\mathrm{HMHP}$ is formed in the reaction of $\mathrm{H} 2 \mathrm{COO}$ with water in the following manner:

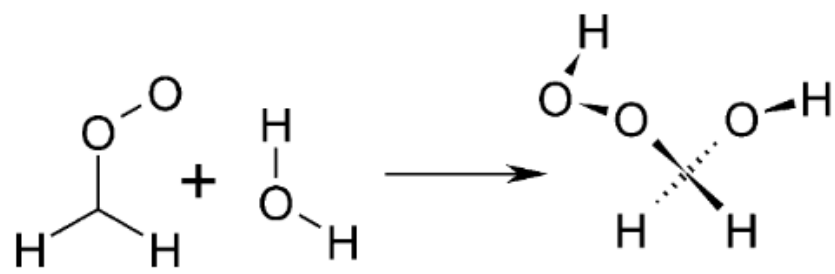

Aplincourt et al. [20] have calculated at level CCSD(T)/6-311G(d,p)//B3LYP/6-31G(d,p) that this reaction proceeds via the formation of a hydrogen-bonded complex between reactants, with complexation energy of $7.2 \mathrm{kcal} / \mathrm{mol}$ and activation energy of 9.5 $\mathrm{kcal} / \mathrm{mol}$. A more recent study by Crehuet et al. [14] at higher theoretical level $\mathrm{CCSD}(\mathrm{T}) / 6-311+\mathrm{G}(2 \mathrm{~d}, 2 \mathrm{p}) / / \mathrm{B} 3 \mathrm{LYP} / 6-311+\mathrm{G}(2 \mathrm{~d}, 2 \mathrm{p})$ resulted in complexation and activation energy estimates of 7.8 and $9.7 \mathrm{kcal} / \mathrm{mol}$, respectively, for the same reaction (2).

In the present study we suggest a novel channel for peroxide formation, via reaction of carbonyl oxide with a water dimer:<smiles></smiles>

\section{Calculation details}

All stationary points, both molecules and transition states were obtained by geometry optimization using the hybrid density functional B3LYP method [21] with the $6-311+G(2 d, 2 p)[22]$ basis sets. To ensure the nature of the stationary points, either minima or saddle points, the har-monic vibrational frequencies were calculated. They were also employed to estimate zero-point vibration energy (ZPE) and thermodynamic contribution to the enthalpy and free energy for $\mathrm{T}=298.15 \mathrm{~K}$. Additionally, intrinsic reaction co-ordinate calculations (IRC) were performed to examine the correspondence of the calculated transition states to the reactants and products. Finally, single-point calculations at the $\operatorname{CCSD}(\mathrm{T}) / 6-311+\mathrm{G}(2 \mathrm{~d}, 2 \mathrm{p})$ level [23] were performed using geometries of the B3LYP/6- 
$311+\mathrm{G}(2 \mathrm{~d}, 2 \mathrm{p})$ optimized structures to obtain more accurate energy estimations. The basis set superposition error (BSSE) was calculated according to the function counterpoise method [24] at the $\operatorname{CCSD}(\mathrm{T})$ level of theory, which included the terms due to intramolecular deformation of the monomers in the complex geometry. All these calculations were performed using the GAUSSIANAUSSIAN98 program package [25].

\section{Results and discussion}

All calculated relative reaction and activation energies, enthalpies and free energies are shown in Tables 1 and 2. We used the following designations to describe stationary structures: $M$ is the minima of energy and TS is the transition states. Fig. 1depicts a relative enthalpy diagram for both pathways. The geometries obtained for molecular structures are given in Figs. 2 and 3.

Table 1

Relative energies $\Delta E$, relative enthalpies $\Delta H(298)$, relative free energies $\Delta G(298)(\mathrm{kcal} / \mathrm{mol})$ for optimized structures at B3LYP and $\operatorname{CCSD}(\mathrm{T})$ levels of theory using the 6-311+G(2d,2p) basis set for the reaction between $\mathrm{H}_{2} \mathrm{COO}$ and $\mathrm{H}_{2} \mathrm{O}$

\begin{tabular}{|c|c|c|c|c|c|c|c|}
\hline \multirow[t]{2}{*}{ Structure } & \multirow[t]{2}{*}{ Relative to } & \multicolumn{3}{|c|}{ B3LYP } & \multicolumn{3}{|l|}{$\operatorname{CCSD}(\mathrm{T})$} \\
\hline & & $\Delta E$ & $\Delta H$ & $\Delta G$ & $\Delta E$ & $\Delta H$ & $\Delta G$ \\
\hline $\mathrm{H}_{2} \mathrm{COO}+\mathrm{H}_{2} \mathrm{O}$ & & 0.0 & 0.0 & 0.0 & 0.0 & 0.0 & 0.0 \\
\hline M1 & $\mathrm{H}_{2} \mathrm{COO}+\mathrm{H}_{2} \mathrm{O}$ & -6.8 & -6.6 & 1.8 & $-7.4(-5.8)^{\mathrm{a}}$ & $-7.2(-5.6)^{\mathrm{a}}$ & $2.6(1.0)^{\mathrm{a}}$ \\
\hline TS1 & M1 & 9.2 & 7.1 & 10.6 & 10.2 & 8.3 & 13.3 \\
\hline M2 & TS1 & -40.9 & -40.5 & -41.3 & -44.3 & -43.9 & -42.1 \\
\hline
\end{tabular}

${ }^{\mathrm{a}}$ BSSE corrected energy.

Table 2

Relative energies $\Delta E$, relative enthalpies $\Delta H(298)$, relative free energies $\Delta G(298)(\mathrm{kcal} / \mathrm{mol})$ for optimized structures at B3LYP and $\mathrm{CCSD}(\mathrm{T})$ levels of theory using the $6-311+\mathrm{G}(2 \mathrm{~d}, 2 \mathrm{p})$ basis set for reaction of $\mathrm{CI}$ with two water molecules

\begin{tabular}{|c|c|c|c|c|c|c|c|}
\hline \multirow[t]{2}{*}{ Structure } & \multirow[t]{2}{*}{ Relative to } & \multicolumn{3}{|c|}{ B3LYP } & \multicolumn{3}{|l|}{$\operatorname{CCSD}(\mathrm{T})$} \\
\hline & & $\Delta E$ & $\Delta H$ & $\Delta G$ & $\Delta E$ & $\Delta H$ & $\Delta G$ \\
\hline$\left(\mathrm{H}_{2} \mathrm{O}\right)_{2}$ & $2 \mathrm{H}_{2} \mathrm{O}$ & -2.8 & -3.3 & 3.8 & $-3.2(-2.2)^{\mathrm{a}}$ & $-3.7(-2.7)^{\mathrm{a}}$ & $5.6(4.6)^{\mathrm{a}}$ \\
\hline M3 & $\mathrm{H}_{2} \mathrm{COO}+2 \mathrm{H}_{2} \mathrm{O}$ & -14.2 & -14.3 & 3.6 & -15.4 & -15.5 & 6.0 \\
\hline M3 & $\mathrm{H}_{2} \mathrm{COO}+\left(\mathrm{H}_{2} \mathrm{O}\right)_{2}$ & -11.4 & -11.1 & -0.1 & -12.2 & -11.9 & 0.4 \\
\hline M4a & $\mathrm{H}_{2} \mathrm{COO}+2 \mathrm{H}_{2} \mathrm{O}$ & -14.4 & -14.9 & 4.2 & $-15.5(-13.3)^{\mathrm{a}}$ & $-16.0(-13.8)^{\mathrm{a}}$ & $6.9(4.7)^{\mathrm{a}}$ \\
\hline M4a & $\mathrm{H}_{2} \mathrm{COO}+\left(\mathrm{H}_{2} \mathrm{O}\right)_{2}$ & -11.6 & -11.6 & 0.4 & -12.4 & -12.4 & 1.3 \\
\hline M4b & $\mathrm{H}_{2} \mathrm{COO}+2 \mathrm{H}_{2} \mathrm{O}$ & -14.5 & -15.0 & 4.2 & $-15.7(-13.5)^{\mathrm{a}}$ & $-16.2(-14.0)^{\mathrm{a}}$ & $6.8(4.6)^{\mathrm{a}}$ \\
\hline M4b & $\mathrm{H}_{2} \mathrm{COO}+\left(\mathrm{H}_{2} \mathrm{O}\right)_{2}$ & -11.7 & -11.7 & 0.4 & -12.6 & -12.5 & 1.2 \\
\hline TS2a & M4a & 3.7 & 1.2 & 4.6 & 6.6 & 4.1 & 8.3 \\
\hline TS2b & M4b & 3.9 & 1.4 & 4.8 & 6.9 & 4.4 & 8.5 \\
\hline M5a & TS2a & -33.2 & -32.4 & -34.0 & $-38.4(-36.5)^{\mathrm{a}}$ & $-37.6(-35.7)^{\mathrm{a}}$ & $-36.3(-34.4)^{\mathrm{a}}$ \\
\hline M5b & TS2b & -33.7 & -32.8 & -34.5 & $-39.3(-37.4)^{\mathrm{a}}$ & $-38.4(-36.5)^{\mathrm{a}}$ & $-37.1(-35.2)^{\mathrm{a}}$ \\
\hline
\end{tabular}

${ }^{\mathrm{a}}$ BSSE corrected energy.

\subsection{Reaction of carbonyl oxide with water}

We confirmed the previous calculations, $[14,20,26]$ in which the reaction of carbonyl oxide with water proceeds via the formation of the hydrogen-bond complex M1(Fig. 2). We estimated the complexation energy to be $7.4 \mathrm{kcal} / \mathrm{mol}$ (BSSE corrected) $5.8 \mathrm{kcal} / \mathrm{mol}$ ) and the energy barrier of this reaction mode was calculated to be $10.2 \mathrm{kcal} / \mathrm{mol}$. Upon the formation of M1, the reaction was found to proceed via the 


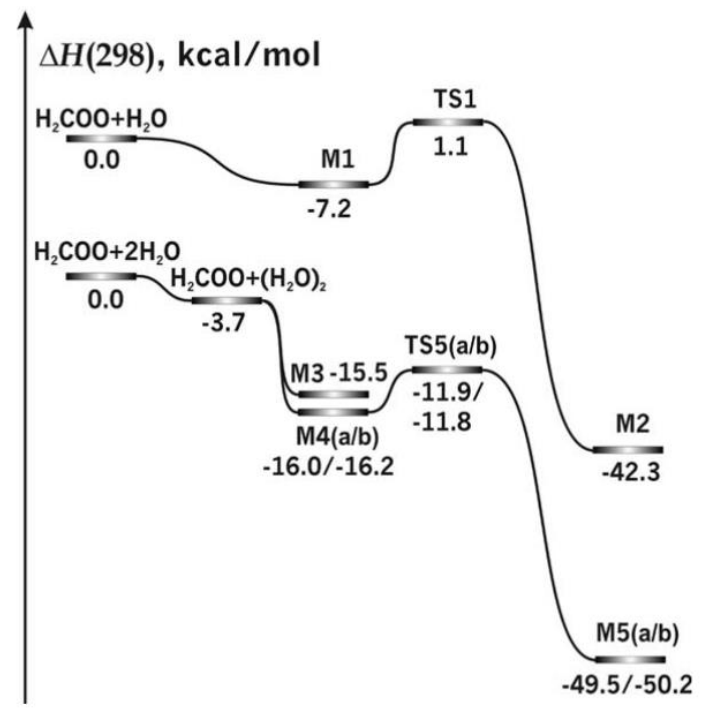

Fig. 1. Enthalpy diagram for the reactions of carbonyl oxide with water and water dimer. transition structure TS1, leading to the product M2- HMHP. This process occurred through cleavage of the $\mathrm{H}-\mathrm{O}$ bond of the water molecule. This bond in the transition state was found to be slightly longer $(\mathrm{R}(\mathrm{HO})=1.064 \AA)$ than in the water molecule $(\mathrm{R}(\mathrm{HO})=0.961 \AA)$. Finally, the hydrogen forms a bond with the terminal oxygen atom of carbonyl oxide while the HO fragment connects to the carbon atom of the carbonyl oxide
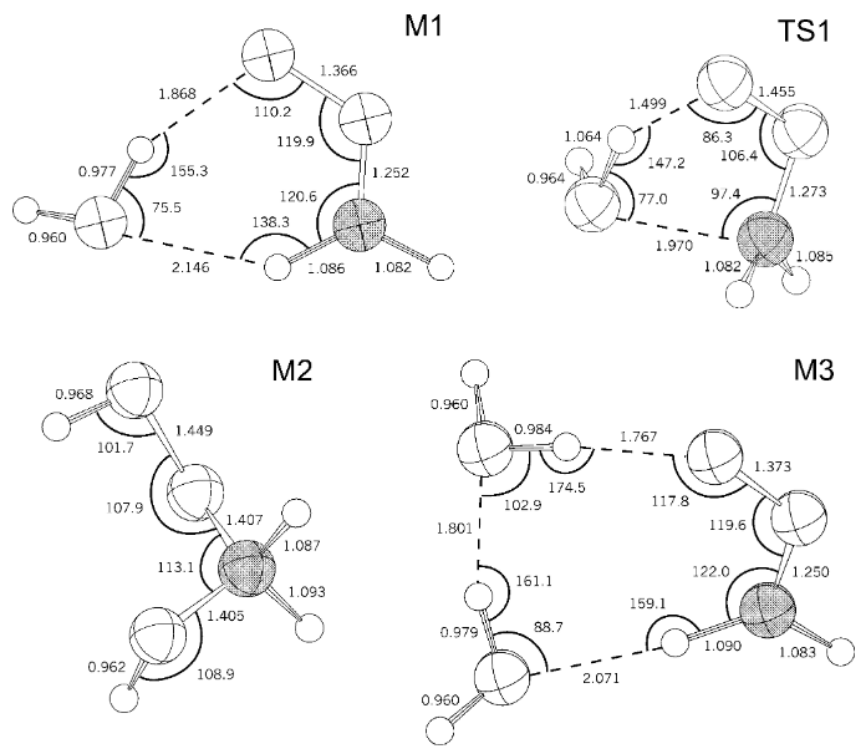

Fig. 2. Selected geometrical parameters of the B3LYP/6-311+G(2d,2p) optimized structures for the reaction $\mathrm{H}_{2} \mathrm{COO}+\mathrm{H}_{2} \mathrm{O}$ and complex $\mathrm{H}_{2} \mathrm{COO} \cdots 2 \mathrm{H}_{2} \mathrm{O}$.

\subsection{Carbonyl oxide-water dimer reaction}

It has been well established that the gas-phase reaction with a water dimer can have a lower activation energy than the reaction with one water molecule, e.g., reactions of ketenimine [27], ketene [28], sulphur trioxide [29], carbon dioxide[30,31]. Hence, we may suspect that the assistance of the second water molecule will lead toa decrease of the energy barrier in HMHP formation.

In a manner similar to the previous pathway (Section 3.1), the reaction of carbonyl oxide with the water dimer was found to proceed via the formation of the hydrogen-bond complex. This three-membered complex should be more stable than its two-membered counterpart, due to the formation of additional hydrogen bonds. Asshown 
in Figs. 2 and 3, two types of such complexes were possible: M3 and M4, the later having two conformers: M4a and M4b. All were found to possess three hydrogen bonds between carbonyl oxide and two molecules of water. One bond connected the terminal oxygen atom of carbonyl oxide to the hydrogen atom of one water molecule. The second bond linked the two water molecules to each other. The third bond linked the oxygen atom of the second water molecule to either the hydrogen atom or the carbon atom of carbonyl oxide (M3 or M4, respectively). Table 2 summarises our calculations of relative energies, enthalpies and free energies for the reaction of carbonyl oxide with the waterdimer.M4a/b complexes were found to be slightly more stable than theM3structure. The stabilisation energies were estimated at 15.5 and $15.7 \mathrm{kcal} / \mathrm{mol}$ forM4aandM4b, respectively, compared to $15.4 \mathrm{kcal} / \mathrm{mol}$ forM3. The BSSE corrected complexation energies were calculated to be 13.3 for M4aand $13.5 \mathrm{kcal} / \mathrm{mol}$ for M4b.

Our calculations demonstrate that the reaction pathway from $M 4 a / b$ via TS4a/b led to the formation of HMHP and a water molecule. In this scenario, after cleavage of the $\mathrm{H}-\mathrm{O}$ bond of the first water molecule, the hydrogen atom bonded to the terminal oxygen atom of carbonyl oxide, resulting in the formation of a peroxide group.

Simultaneously, the remnants of the cleaved water molecule took a hydrogen atom from the second water molecule to compensate for the loss of its hydrogen. The HO fragment formed upon hydrogen separation from the second water molecule bonded to the carbon atom of carbonyloxide. The products of reaction (3), HMHP and a water molecule could generate another hydrogen bond complexM5, withM5aandM5bstructures. The stabilization energies for M5a and M5bwere estimated to be 6.4 and $7.3 \mathrm{kcal} / \mathrm{mol}(4.6$ and $5.5 \mathrm{kcal} / \mathrm{mol}$ with BSSE correction), respectively.

The major sink for the HMHP under laboratory conditions has been assumed to be its heterogeneous decomposition into $\mathrm{HCOOH}$ and $\mathrm{H}_{2} \mathrm{O}[16]$. Upon photolysis in the atmosphere, the HMHP can undergo decomposition via peroxide bond cleavage and lead to the formation of $\mathrm{HOCH}_{2} \mathrm{O}$ and $\mathrm{HO}$ radicals [32]. A complexation involving the formation of the hydrogen bonds can stabilize the peroxides [33]. Therefore, we may expect that the complexesM5a/b formed in reaction (3) are more thermodynamically stable than isolated HMHP. Furthermore, these complexes have enough excess energy to undergo a conformation change of the HMHP molecule following reactions (4) or (5) [14]:<smiles>CCOO</smiles>

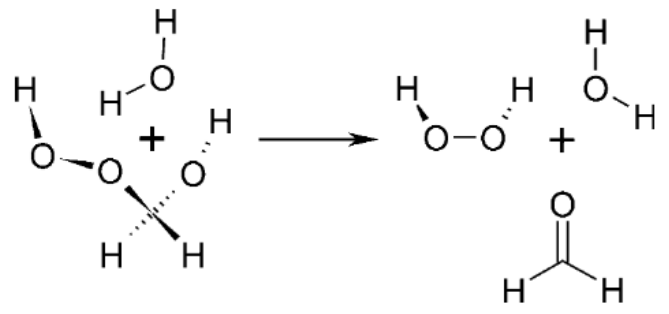


The result of these conformation changes are the formation of formic acid (reaction (4)), as well as formaldehyde and hydrogen peroxide (reaction (5)). In contrast to the reaction of uncomplexed HMHP with water, the reactions of complexesM5a/bare monomolecular, but have the same activation energies. Therefore, these reactions should proceed much faster. We suggest that the preferred pathway is indeed reaction (5), since the formation of formaldehyde and hydrogen peroxide is much more favourable than formic acid, due to its lower energy barrier: $25.6 \mathrm{kcal} / \mathrm{mol}$ for re-action (5) compared to 38.3-40.4 kcal/mol for reaction (4) (calculated at CCSD(T)//B3LYP/6-311+G(2d,2p) level [14]). Consequentially, we consider that hydrogen peroxide is the product of secondary reactions of HMHP, formed as a hydrogen bonded complex with water in reaction (3). In analogy to some previous studies (e.g., [31,34]),we suspect that reactions of carbonyl oxide upon further addition of water molecule, can have lower activation barriers. This reduction can be caused by larger proton transfer effect due to additional hydrogen bonding.

\subsection{Calculation of ratio of the HMHP formation reactions}

According to the Eyring equation and the rate law, the rates of reactions (2) and (3) are

$$
\begin{gathered}
w_{2}=k_{2}\left[\mathrm{H}_{2} \mathrm{O}\right]\left[\mathrm{H}_{2} \mathrm{COO}\right]=\kappa \frac{k_{B} T}{h} e^{-\frac{\Delta^{\ddagger} G_{2}}{R T}}\left[\mathrm{H}_{2} \mathrm{O}\right]\left[\mathrm{H}_{2} \mathrm{COO}\right] \\
w_{3}=k_{3}\left[\left(\mathrm{H}_{2} \mathrm{O}\right)_{2}\right]\left[\mathrm{H}_{2} \mathrm{COO}\right]=\kappa \frac{k_{B} T}{h} e^{-\frac{\Delta^{\ddagger} G_{3}}{R T}}\left[\left(\mathrm{H}_{2} \mathrm{O}\right)_{2}\right]\left[\mathrm{H}_{2} \mathrm{COO}\right]
\end{gathered}
$$

Where ws are reaction rates, ks are rate constants, $\kappa$ is the transmission coefficient, $\mathrm{k}_{\mathrm{B}}$ is Boltzmann's constant, his Plank's constant, $\Delta^{\neq} G$ s are activation free energies. Hence, the ratio of the reaction rates can be estimated by

$$
\frac{w_{2}}{w_{3}}=\frac{k_{2}\left[\mathrm{H}_{2} \mathrm{O}\right]\left[\mathrm{H}_{2} \mathrm{COO}\right]}{k_{3}\left[\left(\mathrm{H}_{2} \mathrm{O}\right)_{2}\right]\left[\mathrm{H}_{2} \mathrm{COO}\right]}=e^{\frac{\Delta^{\neq} G_{3}-\Delta^{\ddagger} G_{2}}{R T}} \frac{\left[\mathrm{H}_{2} \mathrm{O}\right]}{\left[\left(\mathrm{H}_{2} \mathrm{O}\right)_{2}\right]}
$$

Using calculated free energy barriers for reactions (2) and (3), as shown in Tables 1 and 2, and the recent estimation of the equilibrium constant of water dimerization [35], we calculated that ratio (6) equals 14.3 under typical settings of the marine boundary layer. It is noteworthy that light alkenes are widely observed over the marine boundary layer, and therefore, the formation of carbonyl oxide is indeed possible. We used the mean temperature of $253 \mathrm{~K}$, the water molecule density of $2.6 \times 10^{17}$ molecules $/ \mathrm{cm}^{3}$ and a corresponding dimer concentration of $1.7 \times 10^{15} \mathrm{dimers} / \mathrm{cm}^{3}[35]$. Thus, the reaction of carbonyl oxide with water dimers has importance, especially at low temperature conditions when the water dimer concentration is expected to be more substantial than the typical setting afore mentioned. Our results thus indicate that HMHP yield from the reactions of carbonyl oxide with water dimers can be significant, and hence, these pathways should be considered to properly address the im-pact of ozonolysis. 
(C) This manuscript version is made available under the CC-BY-NC-ND 4.0 license https://creativecommons.org/licenses/by-nc-nd/4.0/

\section{Acknowledgements}

This research is supported by the Centre for Climate and Global Change Research ( $\left.\mathrm{C}^{2} \mathrm{GCR}\right)$, McGill University; Natural Sciences and Engineering Research Council in Canada (NSERC); The Canada Foundation for Innovation (CFI); Le Fonds québécois de recherche sur la nature et les technologies. The calculations were performed on the Beowulf cluster at the Centre for Research in Molecular Modeling (CERMM), Concordia University. We thank A. Khalizov and Q. Timergha-zin for valuable suggestions. We also thank L.-A.Joseph, D. Matthews and E. Henderson for proofreading the manuscript.

\section{References}

[1] M.T. Benjamin, M. Sudol, L. Bloch, A.M. Winer, Atmos.Environ. 30 (1996) 1437.

[2] R. Atkinson, Atmos. Environ. 34 (2000) 2063.

[3] S.E. Paulson, J.J. Orlando, Geophys. Res. Lett. 23 (1996)3727.

[4] P.A. Ariya, R. Sander, P.J. Crutzen, J. Geophys. Res.[Atmos.] 105 (2000) 17721.

[5] M. Lee, B.G. Heikes, D.W. OÕSullivan, Atmos. Environ. 34(2000) 3475.

[6] R. Criegee, G. Wenner, Annales 564 (1949) 9.

[7] S. Hatakeyama, H. Akimoto, Res. Chem. Intermed. 20(1994) 503.

[8] H. Niki, P.D. Maker, C.M. Savage, L.P. Breitenbach,Chem. Phys. Lett. 46 (1977)

327.

[9] J.M. Anglada, R. Crehuet, J. Maria Bofill, Chem.-Eur.J. (1999) 1809.

[10] A.S. Hasson, G. Orzechowska, S.E. Paulson, J. Geophys.Res. [Atmos.] 106 (2001) 34131.

[11] O. Horie, G.K. Moortgat, Atmos. Environ., Part A 25A(1991) 1881.

[12] S.E. Paulson, J.H. Seinfeld, Environ. Sci. Technol. 26(1992) 1165.

[13] A.S. Hasson, A.W. Ho, K.T. Kuwata, S.E. Paulson,J. Geophys. Res. [Atmos.] 106 (2001) 34143.

[14] R. Crehuet, J.M. Anglada, J.M. Bofill, Chem.--Eur.J. (2001) 2227.

[15] K.H. Becker, K.J. Brockmann, J. Bechara, Nature (Lon-don) 346 (1990) 256.

[16] P. Neeb, F. Sauer, O. Horie, G.K. Moortgat, Atmos.Environ. 31 (1997) 1417.

[17] F. Sauer, C. Schafer, P. Neeb, O. Horie, G.K. Moortgat,Atmos. Environ. 33 (1999) 229.

[18] S. Hatakeyama, H. Bandow, M. Okuda, H. Akimoto,J. Phys. Chem. (1981) 2249.

[19] S. Gaeb, E. Hellpointner, W.V. Turner, F. Korte, Nature(London) 316 (1985) 535.

[20] P. Aplincourt, M.F. Ruiz-Lopez, J. Am. Chem. Soc. 122(2000) 8990.

[21] A.D. Becke, J. Chem. Phys. 98 (1993) 5648.

[22] R. Krishnan, J.S. Binkley, R. Seeger, J.A. Pople, J. Chem.Phys. 7 2(1980) 650.

[23] K. Raghavachari, G.W. Trucks, J.A. Pople, M. Head-Gordon, Chem. Phys. Lett. 157 (1989) 479.

[24] P. Valiron, I. Mayer, Chem. Phys. Lett. 275 (1997) 46.

[25] M.J. Frisch et al., GAUSSIANAUSSIAN98, Revision A.7, Gaussian,Pittsburgh, PA, 1998.

[26] J.M. Anglada, P. Aplincourt, J.M. Bofill, D. Cremer,Chem. Phys. Chem. 3 (2002) 215.

[27] M.T. Nguyen, A.F. Hegarty, Theochem 10 (1983) 329.

[28] P.N. Skancke, J. Phys. Chem. 96 (1992) 8065. 
(C) This manuscript version is made available under the CC-BY-NC-ND 4.0 license https://creativecommons.org/licenses/by-nc-nd/4.0/

[29] C.E. Kolb, J.T. Jayne, D.R. Worsnop, M.J. Molina, R.F.Meads, A.A. Viggiano, J. Am. Chem. Soc. 116 (1994)10314.

[30] A. Ikuo, T. Ichikawa, S. Teratani, J. Chem. Software 6(2000) 45.

[31] M.T. Nguyen, G. Raspoet, L.G. Vanquickenborne, P.T.Van Duijnen, J. Phys. Chem. A 101 (1997) 7379.

[32] S. Bauerle, G.K. Moortgat, Chem. Phys. Lett. 309 (1999)43.

[33] A. Engdahl, B. Nelander, Phys. Chem. Chem. Phys. 2(2000) 3967.

[34] E. Uggerud, Int. J. Mass Spectrosc. 182/183 (1999) 13.

[35] N. Goldman, R.S. Fellers, C. Leforestier, R.J. Saykally,J. Phys. Chem. A 105 (2001) 515 